ISSN 0103-9954

\title{
COMPORTAMENTO DE MUDAS DE LEGUMINOSAS ARBÓREAS INOCULADAS COM FUNGOS MICORRÍZICOS ARBUSCULARES
}

\section{BEHAVIOR OF LEGUMINOUS TREES INOCULATED WITH ARBUSCULAR MYCORRHIZAL FUNGI}

\author{
Marcos Vinicius Winckler Caldeira ${ }^{1}$ Eliane Maria Ribeiro da Silva ${ }^{2}$ \\ Avílio A. Franco ${ }^{2}$ Magda Lea Bolzan Zanon ${ }^{3}$
}

\begin{abstract}
RESUMO
O presente trabalho teve como objetivo avaliar o efeito da inoculação com Fungos Micorrízicos Arbusculares (FMA) no crescimento de duas leguminosas (Cassia leiandra e Chamaecrista desvauxii). O delineamento experimental utilizado foi inteiramente casualizado com quatro tratamentos e vinte e cinco repetições. Os tratamentos foram: Clomus clarum (Nicolson \& Schenk), Gigaspora margarita (Becker \& Hall), Fungos Nativos e Testemunha (sem inoculação). As mudas foram cultivadas em substrato com composto orgânico, argila, areia e fosfato natural de rocha na proporção de 6:2:1:1. Cento e sessenta e oito dias após a germinação, foram avaliados diâmetro do colo, altura, biomassa aérea, biomassa subterrânea de raízes grossas e finas, percentagem de colonização micorrízicas. Apesar das mudas de Chamaecrista desvauxii terem apresentado maior percentagem de colonização micorrízica com Gigaspora margarita, não houve efeito da inoculação em nenhuma das variáveis avaliadas. Mudas de Cassia leiandra foram colonizadas igualmente por Glomus clarum, Gigaspora margarita e fungos nativos, no entanto incrementos de biomassa aérea e biomassa subterrânea de raízes finas foram observados apenas nas mudas inoculadas com Glomus clarum.
\end{abstract}

Palavras-chave: Fungos micorrízicos, leguminosas arbóreas, crescimento inicial ou juvenil.

\begin{abstract}
The effect of the inoculation of arbuscular mycorrhizal fungi on the growth of two legume trees (Cassia leiandra and Chamaecrista desvauxii) was evaluated. The experimental design was completely randomized with four treatments and twenty-five repetitions. The treatments were: Glomus clarum (Nicolson \& Schenk), Gigaspora margarita (Becker \& Hall), Native Fungi and Control (without inoculation). The seedlings were cultivated in a substratum composed of compost, clay, sand and natural phosphate in the proportion of 6:2:1:1. One Hundred and sixty eight days after seed germination, stem diameter, height, above-ground biomass, below-ground biomass of thick and

1. Engenheiro Florestal, M.Sc., Acadêmico do Curso de Doutorado em Engenharia Florestal. Escola de Florestas. Universidade Federal do Paraná. CEP: 80035-010. Curitiba. PR.

2. Doutores e Pesquisadores do Centro Nacional de Pesquisa Agrobiológica - CNPAB/EMBRAPA. Antiga Rodovia Rio/SP. CEP: 23850-970. Seropédica/Itaguaí. RJ.

3. Engenheira Florestal, M.Sc., Instituto de Ciências Biológicas. Universidade de Passo Fundo. CEP: 99001-970. Passo Fundo. RS.
\end{abstract}


fine roots, and percent mycorrhizal colonization were evaluated. Although the roots of Chamaecrista desvauxii were colonized with Gigaspora margarita there was no effect of the inoculation on any of the variables measured. Seedlings of Cassia leiandra were colonized by all mycorrhizal fungy, however, there was an increase in the above-ground biomass and below-ground biomass of fine roots only on the seedlings inoculated with Glomus clarum.

Key words: Mycorrhizal fungi, legume trees, seedling growth.

\section{INTRODUÇÃO}

A sucessão florestal em áreas degradas é extremamente limitada e altamente imprevisível devido, principalmente, à ausência de bancos de sementes e à baixa fertilidade do solo, havendo a necessidade de se praticar o reflorestamento com espécies nativas ou exóticas apropriadas (JORDAN, 1991).

Dentre as diversas relações biológicas existentes, destaca-se a simbiose micorrízica, que constitui a regra e não a exceção na natureza, existindo vários tipos de micorriza. As micorrizas arbusculares que são cosmopolitas, são o tipo predominante nas espécies vegetais e de maior importância nos ecossistemas tropicais (ALEXANDER et al., 1992).

As micorrizas arbuscululares (MAs) aumentam a área explorada pelo sistema radicular favorecendo melhor, uso dos nutrientes, principalmente o fósforo. Espécies não micorrizadas ou mesmo colonizadas por fungos micorrízicos arbusculares (FMAs) ineficientes, crescendo em condições de baixa disponibilidade de fósforo, em geral necessitam de mais fertilizantes fosfatados do que plantas eficientemente micorrizadas.

De uma maneira geral, em solos com baixa disponibilidade de fósforo as plantas colonizadas com FMAs apresentam um crescimento mais elevado do que as não colonizadas.

Em leguminosas arbóreas a presença de micorrizas pode contribuir para expandir a área de captação do $\mathrm{P}$, Mo, Zn e outros nutrientes de baixa mobilidade no solo, que são absorvidos principalmente por contato com as raízes, permitindo o crescimento em solos extremamentes pobres e deficientes em nitrogênio. A inoculação conjunta de rizóbio com micorrizas pode acelerar o crescimento das plantas (MOSSE, 1976).

Em solos de baixa fertilidade, a inoculação de leguminosas com rizóbio e fungos micorrízicos aumenta a nodulação, a fixação de nitrogênio e crescimento das leguminosas (COSTA et al., 1990).

O presente estudo tem como objetivo analisar o comportamento juvenil de espécies arbóreas inoculadas com fungos micorrízicos arbusculares.

\section{MATERIAL E MÉTODOS}

O presente trabalho foi conduzido em casa de vegetação localizada, no Centro Nacional de 
Pesquisa de Agrobiologia (EMBRAPA/CNPAB) Seropédica/RJ.

As sementes das espécies de Cassia leiandra (mari-mari) e Chamaecrista desvauxii (rabode-pitu) foram provenientes da região de Porto Trombetas/Pará. As sementes passaram por um processo de quebra de dormência em ácido sulfúrico (95-97\%) por 60 minutos para Cassia leiandra e 10 minutos para Chamaecrista desvauxii. Posteriormente, as sementes foram desinfestadas com peróxido de hidrogênio (30\%) por dois minutos e em seguida lavadas com água estéril.

Após a quebra de dormência as sementes foram colocadas em placas de Petri esterilizadas e levadas ao germinador, a uma temperatura de $34,4^{\circ} \mathrm{C}$ por dois a três dias.

O substrato utilizado foi uma mistura de composto orgânico:argila:areia:fosfato de rocha natural na proporção de 6:2:1:1 respectivamente. Para a esterilização do substrato utilizou-se 0,60 $\mathrm{ml}$ de brometo de metila/kg de solo por 96 horas.

O plantio foi feito em bandejas de isopor com 72 células e em cada bandeja foram utilizadas 25 células, sendo que em cada célula foram colocadas duas sementes e quando as mudas obtiveram dois pares de folhas definitivas foi realizado raleamento deixando uma muda por célula.

Juntamente no momento do plantio das sementes pré-germinadas foi realizada a inoculação com fungos micorrízicos arbusculares. Ao arredor das duas sementes foram colocados trinta esporos.

O delineamento experimental utilizado foi inteiramente casualizado com quatro tratamentos e vinte e cinco repetições. Os tratamentos foram: Glomus clarum (Nicolson \& Schenk), Gigaspora margarita (Becker \& Hall), Fungos Nativos e Testemunha (sem inoculação). O solo do tratamento testemunha foi desinfestado com brometo de metila $(0,60 \mathrm{ml}$ de brometo de metila/kg de solo) Os fungos nativos foram procedentes da rizosfera de plantas mata virgem da região de Porto Trombetas-Pará. A origem natural dos esporos dos fungos micorrízicos Glomus clarum e Gigaspora margarita é da coleção do Centro Nacional de Pesquisa de Agrobiologia - CNPAB/EMBRAPA.

Após cento e sessenta e oito dias foram avaliados os parâmetros: altura, diâmetro à altura do colo, peso seco da parte aérea e raiz, percentagem do comprimento de raízes colonizadas.

Do volume de solo coletado em cada célula foram separadas raízes finas $(<1,0 \mathrm{~mm}$ de diâmetro) para avaliação da colonização micorrízica.

Para verificação da colonização micorrízica, o sistema radicular foi lavado e colocado em papel absorvente para ser retirado o excesso de umidade. Foram retirados $500 \mathrm{mg}$ de raízes finas, onde as mesmas foram lavadas com água destilada e conservadas em etanol 50\%. O clareamento e coloração das raízes foi feito de acordo com a metodologia propostas por KOSKE \& GEMMA (1989).

As raízes foram lavadas com água e deixadas por 6 horas, a $28^{\circ} \mathrm{C}$, em $\mathrm{KOH} 10 \%$, aquecidas a $80^{\circ} \mathrm{C}$ durante 1 hora e lavadas com água. Em seguida foram imersas em $\mathrm{H}_{2} \mathrm{O}_{2} 10$ volumes por 5 minutos, lavadas com água e colocadas em $\mathrm{HCl} 2 \%$ por 5 minutos. Removeu-se o $\mathrm{HCl}$ e as raízes foram coradas com azul de tripano $0,05 \%$ em lactoglicerol (ácido lático, glicerol e água na proporção $1: 1: 1$ ) a $65^{\circ} \mathrm{C}$ durante 7 minutos e então colocadas em lactoglicerol. 
A percentagem do comprimento de raízes finas colonizadas foi avaliado pelo método da placa quadriculada (GIOVANNETTI \& MOSSE, 1980).

Aos cento e sessenta e oito dias após a germinação obteve-se a média por planta para cada variável medida, e com esses valore analisou-se estatisticamente, através do programa SPSS (Statistical Package for the Social Science) versão 7.5 para Windows, comparando os resultados de cada tratamento través do teste de Tukey, ao nível de $\alpha$ 5\% de probabilidade de erro.

\section{RESULTADOS E DISCUSSÃO}

Os resultados apresentados a seguir envolvem análises e comparações dos dados obtidos em casa de vegetação e em laboratório para as duas leguminosas arbóreas estudadas.

\section{Chamaecrista desvauxii}

Com relação a Chamaecrista desvauxii observa-se que a inoculação com fungos micorrízicos não favoreceu o crescimento das mudas nos parâmetros analisados (Tabela 1).

TABELA 1: Altura (h), diâmetro à altura do colo (d), biomassa aérea (BA), biomassa subterrânea de raízes grossas - BSRG (> que 1,0 mm de diâmetro) e biomassa subterrânea de raízes finas - BSRF (< que 1,0 mm de diâmetro) em mudas de Chamaecrista desvauxii, inoculadas ou não com FMA, aos 168 dias após a germinação.

\begin{tabular}{l|c|c|c|c|c}
\hline \multicolumn{1}{c}{ Tratamentos } & $\mathrm{h}(\mathrm{cm})^{1}$ & $\mathrm{~d}(\mathrm{~cm})^{1}$ & $\mathrm{BA}^{1}$ & BSRG $^{1}$ & BSRF $^{1}$ \\
\hline Glomus clarum & $42,58 \mathrm{a}$ & $0,21 \mathrm{a}$ & $0,84 \mathrm{a}$ & $0,08 \mathrm{a}$ & $0,05 \mathrm{a}$ \\
Gigaspora margarita & $39,97 \mathrm{a}$ & $0,21 \mathrm{a}$ & $0,84 \mathrm{a}$ & $0,07 \mathrm{a}$ & $0,07 \mathrm{a}$ \\
Fungos Nativos & $41,50 \mathrm{a}$ & $0,24 \mathrm{a}$ & $1,03 \mathrm{a}$ & $0,10 \mathrm{a}$ & $0,07 \mathrm{a}$ \\
Testemunha & $35,67 \mathrm{a}$ & $0,18 \mathrm{a}$ & $0,86 \mathrm{a}$ & $0,06 \mathrm{a}$ & $0,04 \mathrm{a}$ \\
\hline Coeficiente de Variação $(\%)$ & 26,75 & 23,05 & 50,99 & 46,30 & 62,15 \\
\hline
\end{tabular}

${ }^{1}$ g. planta1; Médias seguidas com uma mesma letra são significativamente diferentes, pelo teste Tukey, ao nível $\alpha 5 \%$ de probabilidade de erro.

A maior percentagem de colonização micorrízica foi observada em mudas inoculadas com Gigaspora margarita, sendo que mudas inoculadas com Glomus clarum e fungos nativos foram equivalentes (Tabela 2).

Verifica-se neste trabalho que não existe uma correlação entre a percentagem de colonização micorrízica e a resposta da planta (Tabela 1 e 2). Isto pode ser verificado na literatura onde, segundo LOUREIRO \& SILVA (1993) verificaram que para Aeschynomene fluminenses inoculadas com Glomus occultum, mesmo apresentando a menor percentagem do comprimento de raízes finas colonizadas, foi superior ao controle sem FMVA em altura diâmetro à altura do colo, peso da matéria seca de parte aérea e raízes, volume de raízes e número de nódulos, equivalendo-se a outros tratamentos com FMVA. 
TABELA 2: Percentagem do comprimento de raízes finas (< que 1,0mm de diâmetro) colonizadas com FMA em mudas de Chamaecrista desvauxii, aos 168 dias após a germinação.

\begin{tabular}{lcc}
\hline \multicolumn{1}{c|}{ Tratamentos } & Raízes colonizadas (\%) \\
\hline Glomus clarum & $6,4 \mathrm{~b}$ \\
Gigaspora margarita & $14,3 \mathrm{a}$ \\
Fungos Nativos & $6,9 \mathrm{~b}$ \\
Testemunha & $0,0 \mathrm{c}$ \\
\hline
\end{tabular}

Médias seguidas com uma mesma letra não são significativamente diferentes, pelo teste Tukey, ao nível $\alpha$ 5\% de probabilidade de erro.

Conforme realçado por LOPES (1980) a comparação de valores absolutos de percentagem de colonização em diferentes trabalhos deve ser feita com cuidado porque alguns métodos superestimam esses valores (GIOVANETTI \& MOSSE, 1980).

Mudas de Adenanthera pavonina inoculadas com Glomus macrocarpum tiveram um aumento significativo na produção de biomassa aérea e biomassa subterrânea de raízes grossas entretanto no presente trabalho não foi observado uma maior produção de biomassas nas mudas, inoculadas com o gênero Glomus. Contudo, as maiores percentagens de colonização micorrízica foram verificadas em mudas inoculadas com Glomus clarum, Glomus macrocarpum e fungos nativos (CALDEIRA et al., 1997a).

CALDEIRA et al. (1997b) observaram que as maiores percentagens de colonização micorrízica em Copaifera martii foram com Glomus clarum e Gigaspora margarita. Entretanto, mudas de Dimorphandra macrostachya inoculadas com Gigaspora margarita e fungos nativos foram as que tiveram as maiores taxas de colonização micorrízica.

Cabe aqui ressaltar que o desenvolvimentos das mudas inoculadas com FMAs é função de vários fatores entre eles: espécie florestal, nutrição, substrato, tipo de fungos micorrízicos, $\mathrm{pH}$ do solo.

\section{Cassia leiandra}

No que se refere o desenvolvimento de mudas de Cassia leiandra a Tabela 3 mostra que a inoculação ou não com fungos micorrízicos não influenciou o crescimentos em altura, diâmetro e biomassa subterrânea de raízes grossas. Contudo, mudas inoculadas com Glomus clarum tiveram uma maior produção de biomassa aérea e biomassa subterrânea de raízes finas.

Através da Tabela 3 pode-se observar que a menor produção de biomassa subterrânea de raízes finas foi em mudas inoculadas com fungos nativos e testemunha.

Trabalho realizado por CALDEIRA et al. (1997a) observaram que mudas de Enterelobium schomburgkii inoculadas com Glomus clarum e Glomus macrocarpum tiveram aumento significativo na biomassa aérea, biomassa subterrânea de raízes finas e percentagem de colonização micorrízica. 
TABELA 3: Altura (h), diâmetro à altura do colo (d), biomassa aérea (BA), biomassa subterrânea de raízes grossas - BSRG (> que 1,0 mm de diâmetro) e biomassa subterrânea de raízes finas - BSRF (< que 1,0 mm de diâmetro) em mudas de Cassia leiandra, inoculadas ou não com FMA, aos 168 dias após a germinação.

\begin{tabular}{l|c|c|c|c|c}
\hline \multicolumn{1}{c}{ Tratamentos } & $\mathrm{h}(\mathrm{cm})^{1}$ & $\mathrm{~d}(\mathrm{~cm})^{1}$ & $\mathrm{BA}^{1}$ & BSRG $^{1}$ & BSRF $^{1}$ \\
\hline Glomus clarum & $10,30 \mathrm{a}$ & $0,29 \mathrm{a}$ & $1,65 \mathrm{a}$ & $0,24 \mathrm{a}$ & $0,19 \mathrm{a}$ \\
Gigaspora margarita & $9,78 \mathrm{a}$ & $0,26 \mathrm{a}$ & $1,15 \mathrm{ab}$ & $0,21 \mathrm{a}$ & $0,14 \mathrm{ab}$ \\
Fungos Nativos & $8,57 \mathrm{a}$ & $0,26 \mathrm{a}$ & $0,74 \mathrm{~b}$ & $0,16 \mathrm{a}$ & $0,09 \mathrm{~b}$ \\
Testemunha & $8,32 \mathrm{a}$ & $0,25 \mathrm{a}$ & $0,95 \mathrm{ab}$ & $0,14 \mathrm{a}$ & $0,07 \mathrm{~b}$ \\
\hline Coeficiente de Variação (\%) & 18,13 & 18,26 & 43,79 & 50,37 & 45,15 \\
\hline
\end{tabular}

g. planta'1; Médias seguidas com uma mesma letra não são significativamente diferentes, pelo teste Tukey, ao nível $\alpha 5 \%$ de probabilidade de erro.

A Tabela 4 mostra que as maiores percentagens do comprimento de raízes finas foram em mudas inoculadas com fungos micorrízicos.

TABELA 4. Percentagem do comprimento de raízes finas (< que 1,0 mm de diâmetro) colonizadas com FMA em mudas de Cassia leiandra, aos 168 dias após a germinação.

\begin{tabular}{l|c}
\hline \multicolumn{1}{c|}{ Tratamentos } & Raízes colonizadas (\%) \\
\hline Glomus clarum & $14,6 \mathrm{a}$ \\
Gigaspora margarita & $11,9 \mathrm{a}$ \\
Fungos Nativos & $9,2 \mathrm{a}$ \\
Testemunha & $0,0 \mathrm{~b}$ \\
\hline
\end{tabular}

Médias seguidas com uma mesma letra não são significativamente diferentes, pelo teste Tukey, ao nível $\alpha$ 5\% de probabilidade de erro.

No que se refere o desenvolvimento de mudas de Mimosa guilandenae com fungos micorrízicos CALDEIRA et al. (1997a) observaram que a inoculação com Glomus clarum e Glomus macrocarpum respectivamente, aumentaram a produção de biomassa aérea e biomassa subterrânea de raízes finas. As maiores percentagens de colonização micorrízica foram também observadas em mudas inoculadas com Glomus clarum e Glomus macrcarpum.

Por mais que nos parâmetros avaliados em ambas espécies a inoculação com FMAs não tiveram um grande aumento significativo no crescimento de mudas a literatura mostra os efeitos positivos da inoculação quanto ao ganho de crescimento em altura, diâmetro à altura do colo e peso seco da parte aérea e de raízes, comparando-se a estudos desenvolvidos com outras espécies (DIEDERICHS, 1982; POPE et al., 1988; BORGES \& CHANEY, 1980), provavelmente alcançados pelo melhora na absorção de nutrientes (ABBOTT \& ROBSON, 1984).

\section{CONCLUSÕES}

Mudas de Cassia leiandra e Chamaecrista desvauxii inoculada ou não com fungos 
micorrízicos não tiveram incrementos na altura, diâmetro e biomassa subterrânea de raízes grossa.

Mudas de Chamaecrista desvauxii inoculada ou não com fungos micorrízicos não tiveram incrementos nos parâmetros avaliados.

As maiores percentagens de colonização micorrízica em mudas de Chamaecrista desvauxii foram obtidas, respectivamente com Gigaspora margarita, fungos nativos e Glomus clarum.

Mudas Cassia leiandra inoculadas com Glomus clarum tiveram incrementos na biomassa aérea e biomassa subterrânea de raízes finas.

\section{REFERÊNCIAS BIBLIOGRÁFICAS}

ABBOTT, L.K.; ROBSON, A.D. The effect of VA mycorrhizae on plant growth. In: POWELL, C.L.; BAGYARAJ, D.J. (eds) VA MYCORRHIZAL. S.I.: CRC Press, 1984. p.113-130.

ALEXANDER, I., AHMAD, N., SEE, L.S. 1992. The role of mycorrhizas in the regenaration of some Malaysian forest trees. Pfil.Trans. R. Soc. Lond.,v.335, p.379-388.

BORGES, R.C.G.; CHANEY, W.R. The response of Acacia scleroxyla Tuss. to mycorrhizal inoculation. The International Tree Crops Journal, v.5, p.191-201, 1988.

CALDEIRA, M.V.W.; SILVA, E.M.R. da; FRANCO, A.A. Influência de fungos micorrízicos arbusculares no crescimento de três leguminosas arbóreas. In: II CONGRESSO FORESTAL Y LATINO-AMERICANO, 1997. Anais... Posada-Misiones, 1997a. Contenido 4, politicas, Economia y Educacion.

CALDEIRA, M.V.W.; SILVA, E.M.R. da; FRANCO, A.A., ZANON, M.L.B. Crescimento de leguminosas arbóreas em resposta a inoculação com fungos micorrízicos arbusculares. Revista Ciência Florestal, Santa Maria, v.7, n.1, p.1-10, 1997 b.

COSTA, N.L., PAULINO, V.T., RODRIGUES, A.N.A. 1990. Effect of vesicular-arbuscular mycorrhizal and phosphate fertilization on growth, nodulation and nitrogen and phosphorus uptake of pigeonpea. Nitrogen Fixing Tree Res. Reports, v.8 p.123-125.

DIEDERICHS, C. Influence of light in the efficacy of vesicular-arbuscular mycorrhiza in tropical subtropical plants. I. Effect of light intensity under greenhouse conditions. Angew Botanik, Berlin, v.56, p.325-333, 1982.

GIOVANNETTI, M., MOSSE, B. 1980. An evaluation of techniques for measurig VA mycorrhizal infection in roots. New Phytol. v.84 p.489-500.

JORDAN, C.F. Nutrient cycling processes and tropical forest management. In: GOMEZ-POMPA, A., WHITMORE, T.C., HADLEY, M. ed. 1991. Rain forest regeneration and management. Paris: The Parthenon Publishing Group, p.159-179.

KOSKE, R.E., GEMMA, J.N. 1989. A modified procedure for staining roots to detect VA mycorrhizas. Micol. Res., v.92 p. 488-505. 
LOPES, E.S. 1980. Eficiência e especificidade das associações micorrízicas do tipo vesiculararbuscular em gramíneas e leguminosas forrageiras e no cafeeiro (Coffea arabica L.). Piracicaba, ESALQ/USP, 111p. Tese de Doutorado.

LOUREIRO, M.F., SILVA, E.M.R.da. 1993. Fungos micorrízicos vesículo-arbusculares e Bradyrhizobium sp. em Aeschynomene fluminenses. In: CONGRESSO BRASILEIRO DE CIÊNCIA DO SOLO, 1993. Resumos... Goiânia: SBCS, 1993. v.1 p.333-334.

MOSSE, B. Role of mycorrhizal in legume nutrition. 1976. In: EXPLOTING THE LEGUMERhizobium SYMBIOSIS IN TROPICAL AGRICULTURE, Vicent, J.M. Whitney, A.S., Bose, J. (eds.) Univ. Hawaii coll. Trop. gric. Misc. Publ. n.145 p.275-292.

POPE, P.E.; CHANEY, W.R.; RHODERS, J.D.; WOODHEAD, S.H. The mycorrhizal dependency of four hardwood tree species. Canadian Journal of Botany, Ottwa, v.61, n.2, p.412-417, 1988. 